\title{
Determination of Polonium Nuclides in a Water Sample with Solvent Extraction Method
}

\author{
M. H. Lee, ${ }^{*}$ C. H. Lee, K. Song, C. K. Kim, and P. Martin ${ }^{\dagger}$ \\ Nuclear Chemistry Research Division, Korea Atomic Energy Research Institute, Daejeon, Korea. *E-mail: mhlee@kaeri.re.kr \\ ${ }^{\dagger}$ International Atomic Energy Agency, IAEA's Laboratories, Seibersdorf and Headquarters, Wagramer Strasse 5, \\ A-1400 Vienna, Austria \\ Received May 3, 2010, Accepted July 14, 2010
}

\begin{abstract}
A method is described for the determination of the Po nuclides in a water sample. After the Po nuclides were purified from interfering elements in a water sample using a manganese dioxide precipitation followed by a solvent extraction method, the Po nuclides were deposited onto the silver plate. A large volume of the water sample was effectively pretreated with manganese dioxide precipitation method. To determine the optimum conditions for plating Po, the effects of the $\mathrm{pH}$, volume, temperature and time on the Po deposition were investigated in hydrochloric acid solution. The investigated determination method of Po nuclides with solvent extraction was applied to a tap water sample.
\end{abstract}

Key Words: Polonium nuclides, Water sample, Solvent extraction

\section{Introduction}

Polonium-210, considering its high radiotoxicity (specific activity; $1.66 \times 10^{14} \mathrm{~Bq} / \mathrm{g}$ ), is the final alpha-emitting daughter nuclide ( $\mathrm{E}_{\alpha} ; 5.304 \mathrm{MeV}$, half-life; 138.4 days) in the natural ${ }^{238} \mathrm{U}$ decay series. Especially, the death of Alexander Litvinenko on 23 rd November 2006 has brought the radiotoxicity of ${ }^{210}$ Po into focus as a hot scientific issue. As a naturally occurring radionuclide, ${ }^{210} \mathrm{Po}$ is present in the atmosphere as a decay product of ${ }^{222} \mathrm{Rn}$ gas. Polonium-210 enters the environment through wet and dry atmospheric deposition processes, so ${ }^{210} \mathrm{Po}$ is useful as a tracer for a study of the processes occurring in environmental systems. ${ }^{1-3}$ From the point of view of the total radiation dose received by human beings, ${ }^{210} \mathrm{Po}$ contributes more to the human body than the environmental levels of anthropogenic radionuclides, such as ${ }^{137} \mathrm{Cs}$ and ${ }^{239,240} \mathrm{Pu}$.

Monitoring ${ }^{210} \mathrm{Po}$ in effluent and natural waters requires a method which is reliable, rapid and sensitive. The most widely used techniques for a determination of ${ }^{210} \mathrm{Po}$ are a spontaneous deposition of Po onto silver from weakly acidic solutions. ${ }^{4-7}$ This method, however, is subject to an interference from oxidants and organic as well as inorganic materials. The presence of interference ions makes this procedure less reliable both by reducing the deposition yield of Po and increasing the thickness of the deposited layer. Therefore, it is necessary to purify the Po from the interference elements and nuclides after coprecipitation of a water sample with ferric hydroxide ${ }^{1,8}$ or manganese. ${ }^{9,10}$ For obtaining a reliable activity concentration of ${ }^{210} \mathrm{Po}$ in water, highly selective chemical methods such as solvent extraction, ${ }^{11}$ ion exchange ${ }^{12}$ and extraction chromatography ${ }^{13}$ are desirable. Recently, highly selective chemical methods of ${ }^{210} \mathrm{Po}$ like an extraction chromatography with Sr-resin in environmental samples have been developed. ${ }^{14-16}$ With a Sr Spec resin, the chemical recoveries of ${ }^{210} \mathrm{Po}$ in environmental samples are so variable that they are sometimes less than $60 \%$. Therefore, it is desirable to evaluate the determination steps of ${ }^{210} \mathrm{Po}$ such as a sample preparation, radioanalytical procedure and source pre- paration to obtain reliable data for ${ }^{210} \mathrm{Po}$ from an analytical method.

In this study, Po nuclides were concentrated with a manganese dioxide precipitation and purified with a solvent extraction method. The deposition conditions for the Po nuclides were investigated on the basis of the chemical yield. The modified determination method for the Po nuclides was applied to a tap water sample.

\section{Experimental}

Materials. All the reagents were of an analytical grade (Merck, Germany). Water was purified using the Milli-Q System. The standard ${ }^{209}$ Po solution and ${ }^{210}$ Po solution were supplied by NIST. Sr-Spec resin (Eichrom Industries, USA) was used for the purification of ${ }^{210}$ Po in a water sample. Silver disc (17 $\mathrm{mm}, 0.3 \mathrm{~mm}$ thickness) was stamped from a fine grade $(>99.9 \%)$ silver plate and cleaned with a few drops of concentrated $\mathrm{HCl}$ before a plating. The disc holder was made of Teflon and stirred with a glass stick with a variable speed control.

Sample preparation. About $1 \sim 3 \mathrm{~L}$ of the tap water samples was taken in a beaker and $10 \mathrm{~mL}$ of concentrated $\mathrm{HCl}$ was added to the sample solution to prevent the radionuclides from sticking to the wall of the beaker. After filtering the water samples with a membrane filter $(0.45 \mu \mathrm{M}), 30 \mathrm{mBq}$ of ${ }^{209}$ Po tracer was added to the sample solution and stirred for $1 \mathrm{~h}$ to ensure a tracer equilibration. Then, $5 \mathrm{~mL}$ of $0.2 \mathrm{M} \mathrm{KMnO}_{4}$ and $5 \mathrm{~mL}$ of $0.3 \mathrm{M} \mathrm{MnCl}_{2}$ were added and the solution was adjusted to $\mathrm{pH} 9$ with $25 \%$ $\mathrm{NH}_{4} \mathrm{OH}$. This solution was stirred for $1 \mathrm{~h}$ and kept for a day in order to allow the precipitate to settle down. The supernatant was decanted carefully so as not to disturb the precipitate and the rest was centrifuged. For the solvent extraction, the precipitate was dissolved with $10 \mathrm{~mL}$ of $1 \% \mathrm{H}_{2} \mathrm{O}_{2}$ in $5 \mathrm{M} \mathrm{HCl}$. Also, the precipitate was dissolved with $10 \mathrm{~mL}$ of $1 \% \mathrm{H}_{2} \mathrm{O}_{2}$ in $2 \mathrm{M} \mathrm{HCl}$ for the extraction chromatography. The sample solution was heated-up on a hot plate at $80 \sim 90{ }^{\circ} \mathrm{C}$ for $30 \mathrm{~min}$ to decompose the peroxide. 
Solvent extraction procedure. The sample solution was transferred into a separate funnel and the beaker was washed with $3 \times 5 \mathrm{~mL}$ of $5 \mathrm{M} \mathrm{HCl}$ to give a total of $20 \mathrm{~mL}$. If the sample solution was a yellow color, a small amount of ascorbic acid was added to the solution until the disappearance of the characteristic yellow $\mathrm{Fe}^{3+}$ color (reduce $\mathrm{Fe}^{3+}$ to $\mathrm{Fe}^{2+}$ ). Po was extracted with 10 $\mathrm{mL}$ of $0.1 \%$ diethylammonium diethyldithiocarbamate (DDTC) in $\mathrm{CH}_{3} \mathrm{CCl}_{3}$ by $5 \mathrm{~min}$ with a shaker $(250 \mathrm{rpm})$. Po was extracted twice with $5 \mathrm{~mL}$ of $0.1 \% \mathrm{DDTC}$ in $\mathrm{CH}_{3} \mathrm{CCl}_{3}$. If the organic phase was colored, Po was extracted with further aliquots until the color disappeared. The organic phase was combined and evaporated to a dryness on a hot plate at a low heat (less than 100 $\left.{ }^{\circ} \mathrm{C}\right)$. The aqueous phase was reserved for the $\mathrm{Pb}, \mathrm{Ra}$, Th and $\mathrm{U}$ analyses. The residue was dissolved with $5 \mathrm{~mL}$ of $65 \% \mathrm{HNO}_{3}$ to decompose the DDTC and evaporated to a dryness on a hot plate at $125^{\circ} \mathrm{C}$. The residue was dissolved with $2 \mathrm{~mL}$ of concentrated $\mathrm{HCl}$ and evaporated to a dryness on a hot plate at $90^{\circ} \mathrm{C}$.

Extraction chromatography procedure. $3 \mathrm{~g}$ of $\mathrm{Sr} \mathrm{Spec} \mathrm{(100} \mathrm{-}$ $150 \mu \mathrm{M}$ ) was soaked in distilled water for $1 \sim 2 \mathrm{~h}$, then filled into a glass chromatographic column (inner diameter $10 \mathrm{~mm}$ ) and washed with $100 \mathrm{~mL}$ of distilled water, $100 \mathrm{~mL}$ of $1 \mathrm{M} \mathrm{HNO}_{3}$ and $100 \mathrm{~mL}$ of $2 \mathrm{M} \mathrm{HCl}$. To regenerate a used column, $50 \mathrm{~mL}$ of distilled water, $10 \mathrm{~mL}$ of EDTA ( $\mathrm{pH}$ adjusted to 7 with $\mathrm{NH}_{3}$ ) and $50 \mathrm{~mL}$ of distilled water before passing $100 \mathrm{~mL}$ of $\mathrm{HCl}$ through the column. The sample solution was transferred into a $250 \mathrm{~mL}$ beaker and the beaker was washed with $4 \times 5 \mathrm{~mL}$ of $2 \mathrm{M} \mathrm{HCl}$ to give a total of $30 \mathrm{~mL}$. The sample solution was passed through a Sr-resin column preconditioned in advance and the beaker was washed with $4 \times 5 \mathrm{~mL}$ of $2 \mathrm{M} \mathrm{HCl}$. The column was then washed with $80 \mathrm{~mL}$ of $2 \mathrm{M} \mathrm{HCl}$. Po and $\mathrm{Pb}$ were eluted through the column with $60 \mathrm{~mL}$ of $6 \mathrm{M} \mathrm{HNO}_{3}$ and $6 \mathrm{M} \mathrm{HCl}$, respectively. The Po fraction was evaporated to nearly a dryness and the organic compounds in the fraction were decomposed with $3 \times 1$ $\mathrm{mL}$ of concentrated $\mathrm{HNO}_{3}$ and $\mathrm{HCl}$. After a decomposition, the residue was dissolved with $2 \mathrm{~mL}$ of concentrated $\mathrm{HCl}$ and evaporated to a dryness on a hot plate at $90{ }^{\circ} \mathrm{C}$.

Source preparation and measurement. Residues were taken with $10 \mathrm{~mL}$ of a deposition solution adjusted to $\mathrm{pH} 0.0$ with $6 \mathrm{M}$ $\mathrm{HCl}$ and the dissolved solution was transferred to a Teflon deposition cell. The beaker was further rinsed with $2 \times 2.5 \mathrm{~mL}$ of a deposition solution. If the sample solution was a yellow color, a small amount of ascorbic acid was added to the solution until the disappearance of the characteristic yellow $\mathrm{Fe}^{3+}$ color. Po was spontaneously deposited in a water bath at $90{ }^{\circ} \mathrm{C}$ for $90 \mathrm{~min}$ with a mechanical stirring. After completion of the deposition, the silver disc was removed, rinsed with distilled water and dried at room temperature. Po was measured by $\alpha$-spectrometry.

Recovery test for ${ }^{209}$ Po in a simulated deposition solution. Through a series of experiments, Po was deposited onto a silver plate with a varying $\mathrm{pH}(-1.0 \sim 5.0)$, time $(0.5 \mathrm{~h} \sim 3 \mathrm{~h})$, volume $(5 \mathrm{~mL} \sim 25 \mathrm{~mL})$ and temperature $\left(30{ }^{\circ} \mathrm{C} \sim 90{ }^{\circ} \mathrm{C}\right)$ with or without a stirring. The plating experiments were performed twice. After a completion of the deposition, the silver disc was removed, washed with distilled water and dried at room temperature. The planchette was then measured by an alpha spectrometry.

Analytical procedure for ${ }^{210}$ Po nuclides in the water. After adding about $30 \mathrm{mBq}$ of ${ }^{209} \mathrm{Po}$ (yield tracer) into the tap water, the activity concentrations of ${ }^{210} \mathrm{Po}$ were determined by the sol-

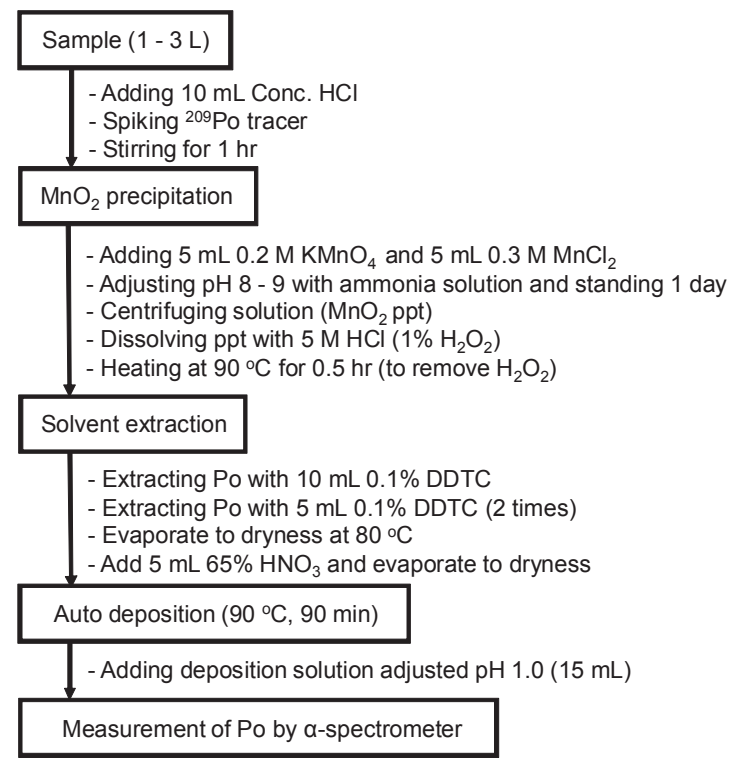

Figure 1. A flow chart of the analytical procedure for ${ }^{210}$ Po nuclides with solvent extraction.

vent extraction and/or extraction chromatographic methods. A flow chart of the analytical procedure for ${ }^{210}$ Po nuclides with solvent extraction in the water is shown in Figure 1.

\section{Results and Discussion}

Pretreatment of water sample. To reliably determine the low level activity concentration of ${ }^{210} \mathrm{Po}$ in a water sample, it is necessary to preconcentrate a large volume of the water sample. Direct evaporation method of a water sample has been mostly used for reducing a small volume of a water sample by careful heating it because of a very simple process. ${ }^{3,17}$ But, for a large amount of a sample $(>2 \mathrm{~L})$, this method is time consuming. Therefore, to reduce the volume of a water sample, coprecipitation methods using ferric hydroxide ${ }^{1,8}$ and manganese ${ }^{9,10}$ have usually been used. When ferric hydroxide is used as a precipitation method in a sample preparation, it is necessary to remove Fe from a sample solution with a solvent extraction like di-isopropyl ether ${ }^{1}$ before a radiochemical separation. Otherwise, the presence of iron may interfere with a purification of Po in the solvent extraction and extraction chromatography as well as auto-deposition even when adding ascorbic acid into the sample solution to reduce $\mathrm{Fe}^{3+}$ to $\mathrm{Fe}^{2+}$. Manganese dioxide precipitation method is useful for concentrating radionuclides from large volumes of water where the radionuclides are considered to exist in a solution. In the classical manganese dioxide precipitation method, the sample solution, which is used to dissolve the precipitate with $1 \% \mathrm{H}_{2} \mathrm{O}_{2}$ in $2 \mathrm{M} \mathrm{HCl}$, takes time to evaporate it to a dryness (two times) with a few $\mathrm{mL}$ of $5 \mathrm{M} \mathrm{HCl}$ for a complete decomposition of the peroxides. However, to save time, the sample solution, which has dissolved the precipitate with $20 \mathrm{~mL}$ of $1 \% \mathrm{H}_{2} \mathrm{O}_{2}$ in $5 \mathrm{M} \mathrm{HCl}$ (solvent extraction) or $2 \mathrm{M} \mathrm{HCl}$ (extraction chromatography) is used for chemical separation after a heating at $90{ }^{\circ} \mathrm{C}$ for $30 \mathrm{~min}$ to decompose the peroxides without an evaporating step to a dryness. Therefore, 
(a)

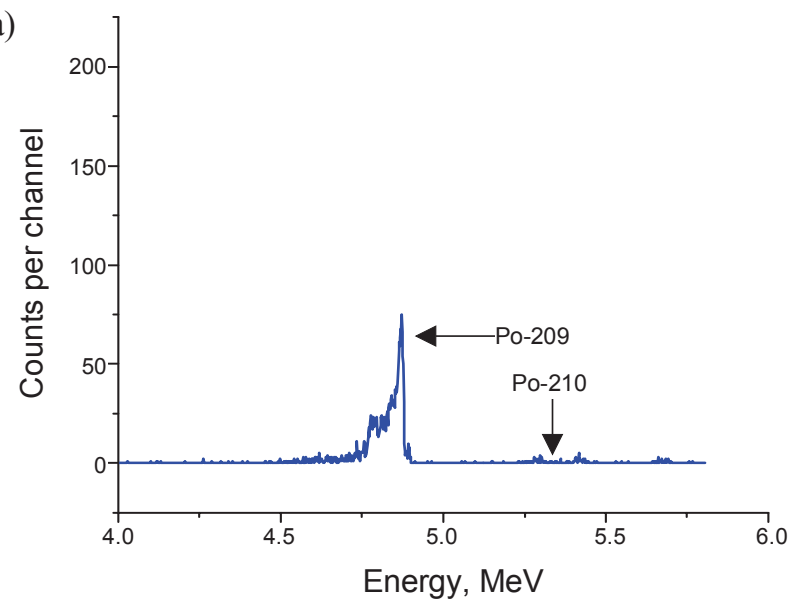

(b)

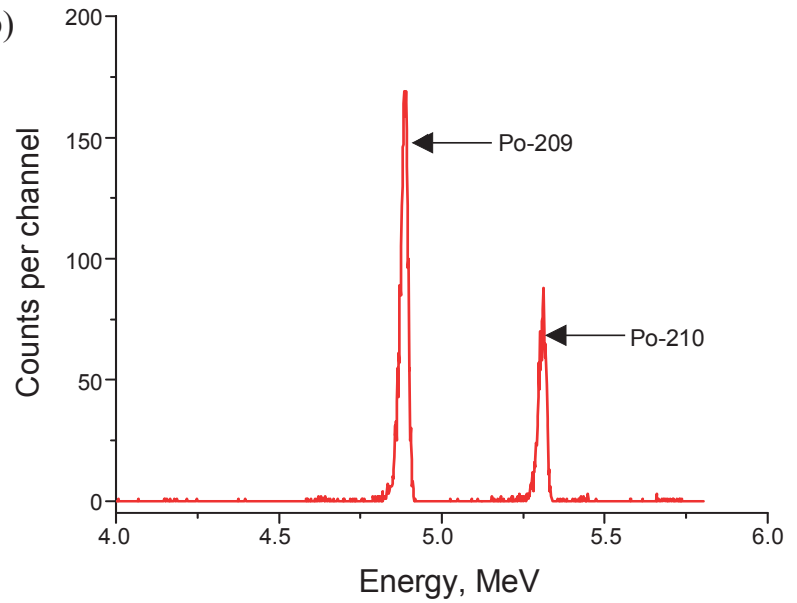

Figure 2. Typical alpha spectra of Po nuclides without chemical separation (a) and with chemical separation (b) in the tap water $(2.5 \mathrm{~L})$.

the sample solution dissolved from the manganese dioxide precipitation can be used directly for a radiochemical separation without using an evaporating step, so the analytical time was reduced by 4 hrs when compared with the classical manganese dioxide precipitation method.

Purification of Po with radiochemical separation method. In water samples that contained a high activity concentration of Po nuclides, a direct source preparation method without a chemical separation has been conventionally used. However, in water samples that contained low level of activity concentration of Po nuclides, for measuring Po nuclides with reliability, it is necessary to concentrate on a large part of the water sample.

After a sample preparation using a coprecipitation method, a direct source preparation without a chemical separation has the advantage of saving time for the determination of ${ }^{210} \mathrm{Po}$. However, for a large amount of a tap water sample (2 L), as shown in Figure 2-a, the peak intensity of ${ }^{210} \mathrm{Po}$ with a direct source preparation was too small to be identified by an alpha spectrometer, even measured over one week. It means that a lot of inorganic materials such as $\mathrm{Ca}^{2+}$ ions and $\mathrm{Mg}^{2+}$ ions contained in the tap water of Austria ${ }^{18}$ co-deposit with Po on the silver plate, as shown in Figure 2-b. Therefore, co-deposition of inorganic materials with Po on the silver plate might affect peak resolution (FWHM) and intensity of Po. Also, in order to
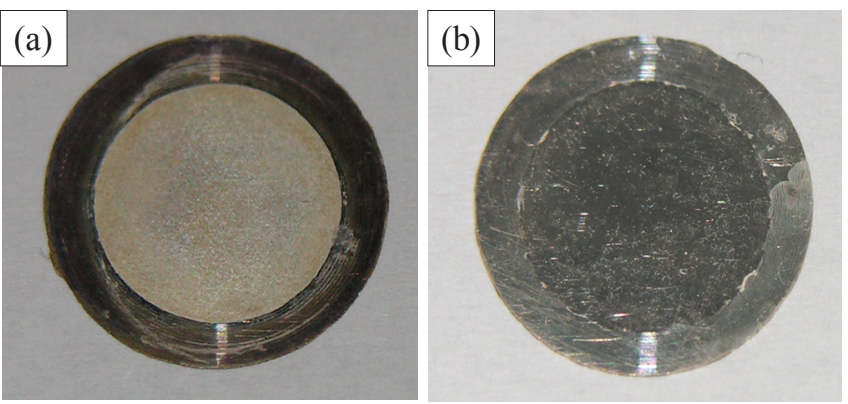

Figure 3. Image of silver plate deposited with Po nuclides without chemical separation (a) and with chemical separation (b) in the tap water $(2.5 \mathrm{~L})$.

prevent a deposition of the interfering elements on the silver plate, the addition of reducing agents and complexing agents, such as ascorbic acid, hydroxylamine hydrochloride and sodium citrate, into the sample solution still resulted in a low Po recovery. Therefore, it is necessary to remove the interference elements from Po with the solvent extraction method ${ }^{8}$ or the extraction chromatography method ${ }^{14}$ prior to a plating for a large volume of a water sample. With the solvent extraction with DDTC, the typical alpha spectra of Po were obtained for a tap water sample, as shown in Figure 3-a. The Po was purified from the interference elements and clearly deposited on the silver plate, as shown in Figure 3-b. However, with the extraction chromatography method with $\mathrm{Sr} \mathrm{Spec}$ resin, a small position of crown ether was partially extracted from Sr Resin that might affect the deposition yield. ${ }^{18}$ So, in this study, the solvent extraction with DDTC was applied to determine Po nuclides in the water.

Deposition of Po. From the chemical aspects, several parameters such as the $\mathrm{pH}$, reducing agent (ascorbic acid) and complexing agent (sodium citrate) influence a spontaneous deposition of Po in a large volume of water. Among the factors affecting the recovery of $\mathrm{Po}$, the $\mathrm{pH}$ level is the main parameter for the deposition of Po for a purified Po sample after a chemical separation. At the fixed deposition time $(2 \mathrm{~h})$, volume $(15 \mathrm{~mL})$ and temperature $\left(90^{\circ} \mathrm{C}\right)$, the effect of the $\mathrm{pH}(-1.0 \sim 5.0)$ was investigated. ${ }^{18}$ Most of the Po was deposited onto the silver plate in the acidic $\mathrm{pH}(0.0 \sim 2.0)$ zone. Over a pH 3.0, the Po is easily adsorbed onto the surface of the beaker and it revealed a reduced recovery. Also, below $\mathrm{pH}-0.5$, the silver was etched, which reduced the recovery and decreased the $\alpha$-peak resolution. ${ }^{18}$ In this study $\mathrm{pH}$ was fixed to 1.0 for depositing Po on the silver plate.

From the physical aspects, the theoretical deposition rate of the Po can be expressed as :

$$
\mathrm{dN} / \mathrm{dt}=\mathrm{K}_{1}\left(\mathrm{~A} \omega^{0.5} / \mathrm{V}\right)\left(\mathrm{N}_{0}-\mathrm{N}_{\mathrm{s}}\right) \exp \left(\mathrm{K}_{2} \mathrm{~T}\right)
$$

where $\mathrm{dN} / \mathrm{dt}$ is the rate of deposition; $\mathrm{K}_{1}$ and $\mathrm{K}_{2}$ are constants; $\mathrm{T}$ is the absolute temperature; $\mathrm{A}$ is the active area; $\mathrm{V}$ is the volume of solution, $\omega$ is the angular velocity of a rotation of a disc; $\mathrm{N}_{0}$ and $\mathrm{N}_{\mathrm{s}}$ are the concentrations of Po in the bulk liquid and at the disc surface respectively. ${ }^{5}$ This equation suggests that the optimum plating conditions would require a high temperature and high angular velocity and a small solution volume. 


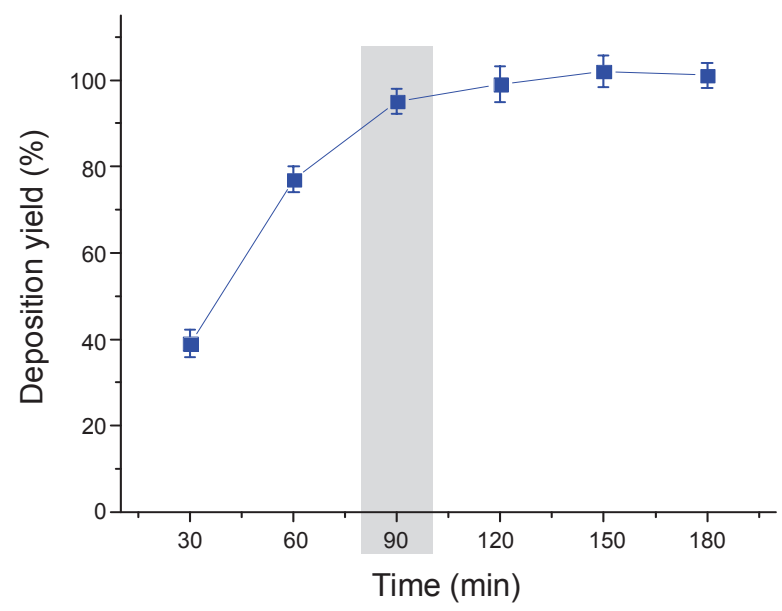

Figure 4. Variation of the deposition yield (mean \pm standard deviation of 2 replicates) with time under the conditions: $\mathrm{pH} 1,90^{\circ} \mathrm{C}$ and $15 \mathrm{~mL}$ of deposition solution.

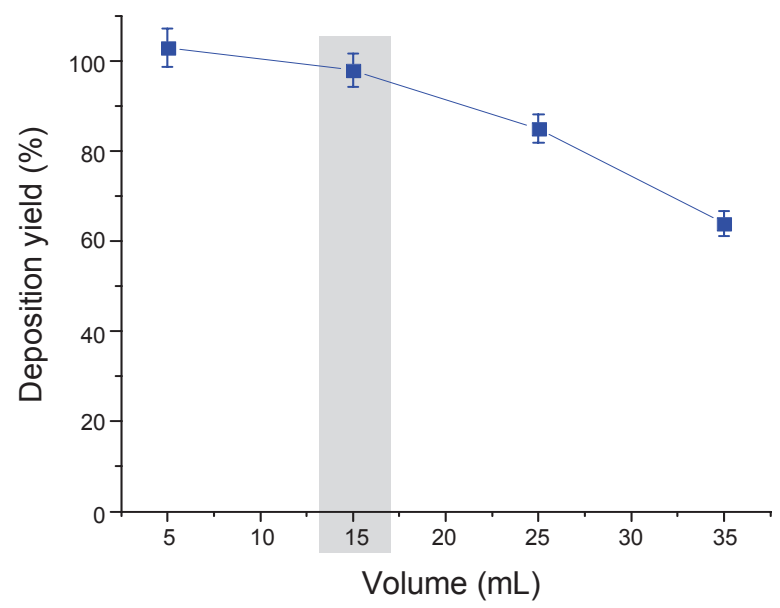

Figure 5. Variation of the deposition yield (mean \pm standard deviation of 2 replicates) with deposition solution under the conditions: $\mathrm{pH} 1$, $90{ }^{\circ} \mathrm{C}$ and 90 minutes of deposition time.

In this study, the recoveries of ${ }^{209} \mathrm{Po}$ from the simulated solution were measured as a function of the time, volume and temperature with or without a stirring. The effect the time from $0.5 \mathrm{~h}$ to $3 \mathrm{~h}$ with a fixed $\mathrm{pH}(0.0)$, volume $(15 \mathrm{~mL})$ and temperature $(90$ ${ }^{\circ} \mathrm{C}$ ) is shown in Figure 4. About $99 \%$ of the Po was deposited onto the silver plate at over $1.5 \mathrm{~h}$. With deposition times longer than $3 \mathrm{~h}$, the surface of the silver plate may be etched by the acidic solution which reduces the recovery. As shown in Figure 5 , the maximum deposition yields were obtained with a volume of $5 \mathrm{~mL}$. In the environmental samples, however, the deposition volume $(5 \mathrm{~mL})$ is not enough to transfer it to the deposition apparatus, so the deposition volume was fixed to $15 \mathrm{~mL}$ in this study ${ }^{18}$ For a stationary silver disc, the recovery of ${ }^{209}$ Po from the solution at $90^{\circ} \mathrm{C}$ was just $60 \%$ after $1.5 \mathrm{~h}$, as shown in Figure 6 . With a mechanical stirring with a glass rod for $1.5 \mathrm{~h}$, the recovery of ${ }^{209}$ Po was nearly $100 \%$ at $90^{\circ} \mathrm{C}$. Also, with an increasing temperature, the recovery of ${ }^{209} \mathrm{Po}$ was increased. An improvement in the deposition at higher temperatures with a rotation has been explained by the removal of ozone. ${ }^{7}$ The optimum

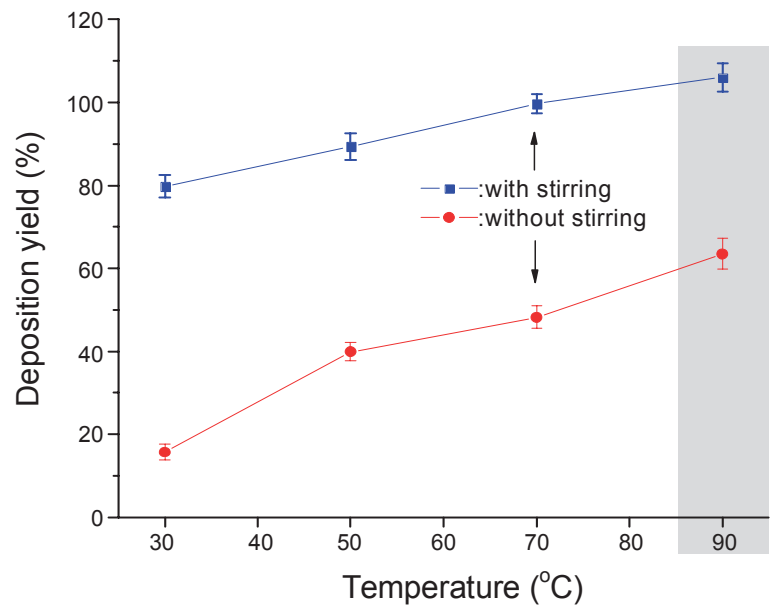

Figure 6. Variation of the deposition yield (mean \pm standard deviation of 2 replicates) with temperature under the conditions: $\mathrm{pH} 1,90^{\circ} \mathrm{C}$ and $15 \mathrm{~mL}$ of deposition time.

Table 1. Optimum conditions for the auto deposition of Po nuclides

\begin{tabular}{lc}
$\mathrm{pH}$ of deposition solution & 1.0 \\
Deposition time & $1.5 \mathrm{~h}$ \\
Deposition volume & $15 \mathrm{~mL}$ \\
Temperature of deposition solution & $90{ }^{\circ} \mathrm{C}$ with stirring \\
\hline
\end{tabular}

conditions for the auto deposition of Po nuclides are presented in the Table 1.

Determination of Po in the watersample. Before determining Po nuclides in the water sample, it is necessary to check the purity and any background levels of ${ }^{210}$ Po that may be introduced from the reagents. This was achieved by following the analytical procedure as describe previously with $2.5 \mathrm{~L}$ of milli-Q water. The reagent blank for ${ }^{210} \mathrm{Po}$ in the milli-Q water with the solvent extraction $(0.014 \pm 0.00011 \mathrm{mBq} / \mathrm{L})$ was lower than that with the extraction chromatography $(0.20 \pm 0.042 \mathrm{mBq} / \mathrm{L})$. This infers that a small amount of Po contained the $\mathrm{Sr}$ resin (crown ether) is eluted with $6 \mathrm{M} \mathrm{HNO}_{3}$. From these results, it is necessary to consider the reagent blank activity of ${ }^{210} \mathrm{Po}$ for the determination of a low level of ${ }^{210}$ Po like a water sample.

The solvent extraction with DDTC was applied for the determination of ${ }^{210} \mathrm{Po}$ in the tap water of Vienna where the activity concentrations of ${ }^{210} \mathrm{Po}$ were measured to be in the range of $1.50 \mathrm{mBq} / \mathrm{L}$ to $3.96 \mathrm{mBq} / \mathrm{L}$ with a mean value of $2.18 \pm 1.06$ $\mathrm{mBq} / \mathrm{L}$. The activity concentrations of ${ }^{210} \mathrm{Po}$ in the tap water of Vienna with the solvent extraction method were similar to those with the extraction chromatography method. The value of MDA with the solvent extraction and extraction chromatographic methods was in the range of $0.0015 \mathrm{mBq} / \mathrm{L}$ to 0.0040 $\mathrm{mBq} / \mathrm{L}$.

\section{Conclusion}

With a manganese dioxide precipitation and the solvent extraction or extraction chromatography methods Po nuclides were reliably purified from interference elements in water samples. The deposition conditions for plating Po have been 
optimized with the deposition parameters such as the $\mathrm{pH}$, volume and temperature of the deposition and deposition time. The developed determination method for ${ }^{210}$ Po with solvent extraction was applied to a tap water sample where the activity concentration of ${ }^{210}$ Po was $2.18 \mathrm{mBq} / \mathrm{L}$.

\section{References}

1. Narita, H.; Harada, K.; Burnett, W. C. Talanta 1989, 36, 925.

2. Peck, G. A.; Smith, J. D. Anal. Chim. Acta 2000, 422, 113.

3. Katzlberger, C.; Wallner, G.; Irlweck, K. J. Radioanal. Nucl. Chem. 2001, 249, 191.

4. Flynn, W. W. Anal. Chim. Acta 1968, 43, 221.

5. Smith, J. D.; Hamilton, T. F. Anal. Chim. Acta 1984, 160, 69.

6. Jia, G.; Belli, M.; Blasi, M.; Marchetti, A.; Rosamilia, S.; Sansone, U. Appl. Radiat. Isotopes 2000, 53, 115.

7. Vesterbacka, P.; Ikäheimonen, T. K. Anal. Chim. Acta 2005, 545, 252

8. Jia, G.; Belli, M.; Blasi, M.; Marchetti, A.; Rosamilia, S.; Sansone,
U. J. Radioanal. Nucl. Chem. 2001, 247, 491.

9. Carvalho, F. P. Sci. Total Environ. 1997, 196, 151.

10. Stepnowski, P.; Skwarzec, B. J. Environ. Radioactiv. 2000, 49, 195.

11. Martin, P.; Hancock, G. J. Supervising Scientist Report 1802004 , AGPS, Canberra

12. Reischmann, F. J.; Trautmann, N.; Herrmann, G. Radiochim. Acta 1984, 36, 139.

13. Ordonez-Regil, E.; Iturbe, J. L. J. Radioanal. Nucl. Chem. 1993, $175,47$.

14. Vajda, N.; LaRosa, J.; Zeisler, R.; Danesi, P.; Kis-Benedek, Gy. J. Environ. Radioactiv. 1997, 37, 355.

15. Biggin, D.; Cook, T.; Mackenzie, B.; Pates, M. Anal. Chem. 2002, 74,671

16. Vrecek, P.; Benedik, L.; Pihlar, B. Appl. Radiat. Isotopes 2004, 60, 717.

17. Martin, P.; Hancock, G. J.; Johnston, A.; Murray, A. S. J. Environ. Radioactiv. 1998, 40, 37

18. Kim, C. K.; Lee, M. H.; Martin, P. J. Radioanal. Nucl. Chem. 2009, 279, 639 . 